\title{
A Case of Pelvic Congestion Syndrome With Chronic Lower Abdominal Pain and Vaginal Spotting in a Woman of Childbearing Age
}

\author{
Junsik Park ${ }^{\mathrm{a}}$, Tae-Hee Kim ${ }^{\mathrm{a}, \mathrm{b}}$, Hae-Hyeog Lee ${ }^{\mathrm{a}}$, Soo-Ho Chung, \\ Dong-Su Jeon ${ }^{\text {a }}$, Seyeon Jang ${ }^{\mathrm{a}}$
}

\begin{abstract}
Pelvic congestion syndrome (PCS), which is said to occur due to ovarian vein incompetence, is a recognized cause of chronic pelvic pain. The association of pelvic congestion with ovarian varicosities is known. Recently, transcatheter embolo-therapy has been shown to be both safe and effective. Here we report a case of PCS that was diagnosed by venography and treated by transcatheter embolization.
\end{abstract}

Keywords: Pelvic Congestion Syndrome; Transcatheter Embolization; Varicose Vein

\section{Introduction}

Pelvic congestion syndrome (PCS) first introduced by Taylor [1] in 1949 is known to cause different levels of spontaneous chronic pelvic pain for period longer than 6 months. This disease incurs vasodilatation in ovarian vein accompanied by blood regurgitation due to malfunction of ovarian venous valve. And, pelvic congestion of venous plexus and varicose veins are found to trigger pelvic pain that are verified by postmortem or pelviscopy [2]. Although it has not been clearly revealed yet, factors that bring anatomical changes are assumed to be influenced by pregnancy, hormone change, innate valve deficiency and stress.

Among various diagnostic image tools that can detect PCS, selective venography is the best choice [3].

\footnotetext{
Manuscript accepted for publication May 16, 2013

${ }^{a}$ Department of Obstetrics and Gynecology, Soonchunhyang University College of Medicine, Bucheon, 420-767, Republic of Korea

${ }^{b}$ Corresponding author: Tae-Hee Kim, Department of Obstetrics and Gynecology, Soonchunhyang University Bucheon Hospital 170 Jomaru-ro, Wonmi-gu, Bucheon-si, Gyeonggi-do, 424-767, Republic of Korea. Email: heeobgy@schmc.ac.kr
}

doi: http://dx.doi.org/10.4021/jmc1304w
PCS has been treated by as medication and hormone therapy with surgical procedures that remove dilated vein. Recently, less invasive and safe methodologies using embolic materials like ovarian venous embolization are being conducted in a number of clinic centers. Their treatment results, safety and efficacy have been introduced in journals abroad [4-9].

The authors of this paper report extensive nature of its pathophysiology, diagnosis, treatment after experiencing the first case of PCS in our university hospital.

\section{Case Report}

A 40-year-old woman has experienced an aggravation of menstrual pain and lower abdominal pain at every menstrual period for last 10 years. Since afternoon in the day before the clinical visit, she had lower abdominal pain like that of supra-pubic tenderness and vaginal spotting with amount of one pad. Her menarche was at age of 15 and menstrual period was 3 days long, regular at 28 days. Menstrual amount was use of $2-3$ pads a day at the maximum, and there was aggravation of menstrual pain and lower abdominal pain at every period. She was divorced 10 years ago. She had 2 times of vaginal delivery and had an artificial abortion with dilatation and curettage 8 days before the clinical visit. She had received subtotal thyroidectomy. The 40-year-old woman's aggravated menstrual pain and lower abdominal pain appeared after her divorce and had several hospitalized experiences. Before 8 days of the clinical visit, after having D\&C at nearby hospital, she had supra-pubic tenderness and vaginal spotting with amount of one pad from the afternoon for which she got hospitalized after visiting emergency room.

At the clinical visit, she had blood pressure of 140/80 $\mathrm{mmHg}$ with pulse rate of 72 times/minute, breathing rate of 20 times/minute, body temperature at $36.8{ }^{\circ} \mathrm{C}$. In chest examination, breathing sound was clear, heart beating was regular, and no heart murmur was detected. In abdominal examination, there was tenderness at left side and supra-pubic area. In obstetrics examination, no peculiarity was found in vulva, vaginal spotting was observed, and cervix was hard in which motion tenderness was detected. There was no other 


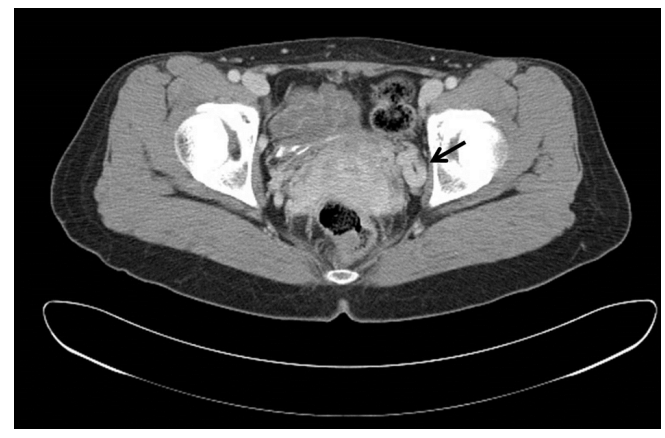

Figure 1. Abdominal computed tomography. Congested varicose vein and dilated left ovarian vein (arrow) were observed.

particular opinion.

At examination, hemoglobin was $12.3 \mathrm{~g} / \mathrm{dL}$ and hematocrit was at $36 \%$, indicating a normal condition. Also, no variation was shown in white blood cell, platelet and blood coagulation. There was no peculiarity in liver function test and renal function. In hepatitis antibody test, HBsAg, HB$\mathrm{cAb}$ were positive and syphilis test was negative. No abnormality was shown in urinalysis.

In both adnexas, congested varicose vein and dilated left ovarian vein were observed to indicate PCS (Fig. 1). For more accurate examination and treatment, transcatheter embolization (TCE) was performed.

Under USG, 9F sheath through right internal jugular vein was inserted until it reached inferior vena cava. Then, 5F DAV's catheter was use to select left renal vein and performed venography. In venography, makely dilated vein with flow toward the uterine venous plexus in left ovarian vein. TCE using coil was performed on left ovarian vein (Fig. 2). After confirming the regurgitation of blood from left renal vein to left ovarian vein, we selected left ovarian vein with $5 \mathrm{~F}$ catheter and conducted embolization on left ovarian vein with four $12 \mathrm{~mm}$ and two $10 \mathrm{~mm}$ coils. After 5 days of hospitalization, there was a relief of pain.
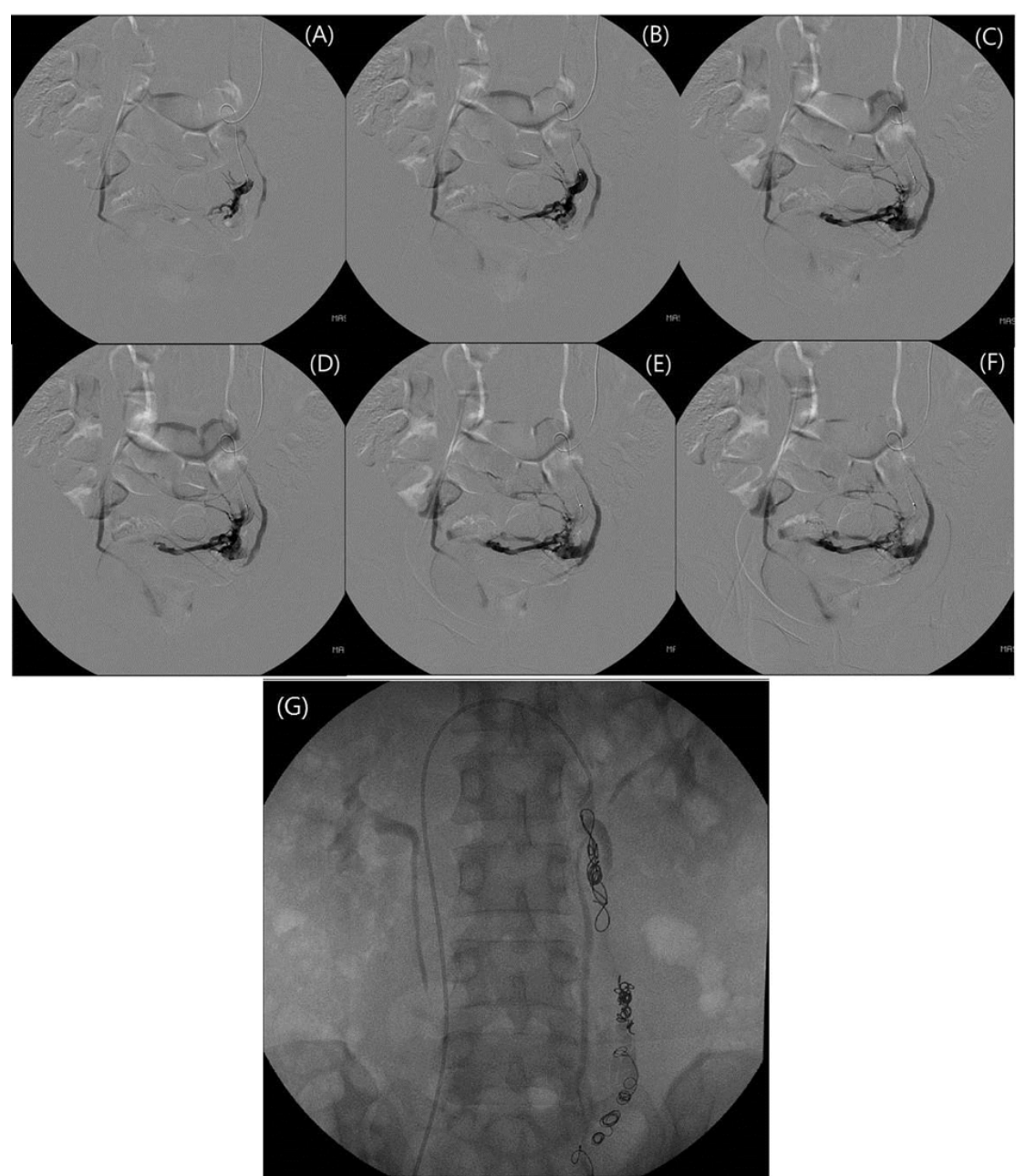

Figure 2. In venography, makely dilated vein with flow toward the uterine venous plexus in left ovarian vein $(A-F)$. Transcatheter embolization using coil was performed on left ovarian vein $(G)$. 


\section{Discussion}

As $10-30 \%$ of outpatients to obstetrics and gynecology department complain of chronic pelvic pain that lasts for longer than 6 months at consistent or spontaneous basis, it has clinical importance [3].

When there is continuation of pelvic pain without a source, PCS can be considered as one of the possibilities [4]. Despite great variance in level and length of pain, the pain gets aggravated at premenstrual period with increased abdominal pressure. PCS is often accompanied by vulvar, perineal and varicose veins. Sometimes, patients complain of bladder urgency, dyspareunia, fatigue or constipation $[3,10]$.

Ovarian varix was found during autopsy of young women deceased of massive hemorrhage by Richet in 1854. Later, in 1928, Cotte had proposed correlation between pelvic pain and ovarian varicose vein, and Talyor came up with the name of 'pelvic congestion syndrome' in 1949 [11].

According to research by pelvic venography on patients with complaints of chronic pelvic pain without a definite cause, in surgical opinion, only congestion in pelvic vein was found in $91 \%$ of the patients without any other peculiarities while serious congestion in pelvic vein was reported in venography. This purports that pelvic varicose vein may be the major cause of pelvic pain.

Although there is no definite cause for PCS, it is believed that several factors work together in a complex mechanism. Mostly, hormone change is responsible for PCS in that PCS occurs mostly in multiparous women while almost absent in post-menopause period. Also, symptoms of PCS are ameliorated when medical ovarian suppression is conducted [12]. In particular, due to hormone changes and pregnant uterus during pregnancy, ovarian vein becomes suppressed and dilated during which increase blood flow damages valve, and thus result in regurgitation of ovarian vein [13].

The fact that PCS mostly occurs in pre-menopause women indicates that PCS is highly related to ovarian function. Pelvic vein torsion due to abnormal location of uterus and ovarian vein's valve defect are also the factors that incur varicose vein in pelvis $[6,11]$. Reviewing several research, ovarian varicose vein occurs from a variety of physical and hormone factors [7]. In most cases of PCS, left ovarian vein is often damaged and this is because renal vein joins from right side of left ovarian vein. On the other hand, right ovarian vein is almost untouched [13].

PCS can be considered only when there is no other disease to explain the pelvic pain with patient's symptoms, physical examination from obstetrics and gynecology department, examination center's opinion, imagery opinion. Unlike other patients, PCS patients are relatively more multiparous and their symptoms may differ with their posture and walking steps. And as for scientific examination, PCS patients tend to have ovarian pressure and pain after sexual intercourse [12].

For methods to detect pelvic congestion and dilation in ovarian veins, there are USG, Computed Tomography (CT), Magnetic Resonance Imaging (MRI), and retrograde venography. In most cases, ultrasonography is conducted first to exclude other pelvic diseases [3]. In USG, one can observe dilated left ovarian vein, regurgitation of vein blood, existence of varicose vein, dilation of spiral vein that passes through uterine myometrium and ovarian polycystic change [14]. In CT examination, regurgitated blood flow of vein can be observed during arterial phase. Also, ovarian vein of which its density increases in the beginning and renal vein can be found using CT [10].

Retrograde venography is often used for PCS diagnosis $[7,10]$. Clinically speaking, when there are over $10 \mathrm{~mm}$ diameter of ovarian vein, congestion in uterine veins and ovarian plexus, pelvic vein at opposite side, pudendal vein, contrast enhance shown in femoral varicose vein, PCS is suspected. 3 To increase pressure in patients' abdomens, retrograde venography is performed under half-standing up posture or valsalva maneuver $[7,10]$.

Treatments are divided into medical treatment and surgical treatment. Non steroid anti-inflammatory drugs can be used for short time period to reduce patients' pain. However, pain may revive after halt of intake and may cause gastrointestinal complication such as heartburn in the long term. Medroxyprogesterone that suppresses ovarian function and Gonadotrophin Releasing Hormone Agonist (GnRHa), are also very effective in pain relief in the short term. Medroxyprogesterone shows amelioration of symptoms in $40 \%$ of the patients, and combined with phycotheraphy, it showed increased in effectiveness to $60 \%$. Such kind of hormone therapy can be applied to relatively young women who want to preserve uterus and its adnexa. However, the long term effectiveness has not been found yet. It may cause complications related to fertility and bone metabolism when used for a long period of time $[15,16]$. In case of hysterectomy and bilateral oophorectomy, about $2 / 3$ of patients had displayed alleviation in symptoms or were cured [12]. On the other hand, ovarian vein ligation demonstrates $73 \%$ of cure, and $78 \%$ experienced amelioration of symptoms [17]. However, disadvantages of vein clipping are longer recovery period, unaesthetic view, post-surgical pain. Moreover, as this cuts nerve that flows to pelvic, symptoms may reappear when collateral channel is formed.

With adoption of more efficient and non-invasive intravascular therapy, aforementioned surgical procedures are nearly not performed. TCE to ovarian vein was adopted by Edward in 1993 [5]. This is mostly performed at diagnostic venography. During the TCE, sclerosant and coil are used to form an embolus within vein for angio-infarction. About $73-78 \%$ of patients were cured or relieved of pain after the procedure [15]. Although embolization therapy has low occurrence of complications (less than 4\%), still there are ovarian thrombo-vasculitis, varix recur, transfer of embolic material, radiation exposure of ovary. According to long-term 
monitoring, there was no negative influence on menstrual period or fertility [18].

Authors of this research are presenting this report with literature review as we have experienced the first PCS in a woman with chronic pelvic pain at the fertile age.

\section{Grant Support}

Authors were not supported by any grant.

\section{Conflict of Interest}

Authors declare no conflict of interest.

\section{References}

1. Taylor HC, Jr. Vascular congestion and hyperemia; their effect on function and structure in the female reproductive organs; the clinical aspects of the congestion-fibrosis syndrome. Am J Obstet Gynecol. 1949;57(4):637653.

2. Beard RW, Highman JH, Pearce S, Reginald PW. Diagnosis of pelvic varicosities in women with chronic pelvic pain. Lancet. 1984;2(8409):946-949.

3. Kennedy A, Hemingway A. Radiology of ovarian varices. Br J Hosp Med. 1990;44(1):38-43.

4. Mavili E, Kahriman G, Tuna IS, Ozcan N. Successful treatment of pelvic congestion syndrome by transcatheter embolization. European Journal of Radiology Extra. 2006;59(1):39-42.

5. Edwards RD, Robertson IR, MacLean AB, Hemingway AP. Case report: pelvic pain syndrome--successful treatment of a case by ovarian vein embolization. Clin Radiol. 1993;47(6):429-431.

6. Capasso P, Simons C, Trotteur G, Dondelinger RF, Henroteaux D, Gaspard U. Treatment of symptomatic pelvic varices by ovarian vein embolization. Cardiovasc Intervent Radiol. 1997;20(2):107-111.

7. Maleux G, Stockx L, Wilms G, Marchal G. Ovarian vein embolization for the treatment of pelvic congestion syn- drome: long-term technical and clinical results. J Vasc Interv Radiol. 2000;11(7):859-864.

8. Tarazov PG, Prozorovskij KV, Ryzhkov VK. Pelvic pain syndrome caused by ovarian varices. Treatment by transcatheter embolization. Acta Radiol. 1997;38(6):10231025.

9. Sichlau MJ, Yao JS, Vogelzang RL. Transcatheter embolotherapy for the treatment of pelvic congestion syndrome. Obstet Gynecol. 1994;83(5 Pt 2):892-896.

10. Rozenblit AM, Ricci ZJ, Tuvia J, Amis ES, Jr. Incompetent and dilated ovarian veins: a common CT finding in asymptomatic parous women. AJR Am J Roentgenol. 2001;176(1):119-122.

11. Hobbs JT. The pelvic congestion syndrome. Br J Hosp Med. 1990;43(3):200-206.

12. Beard RW, Reginald PW, Wadsworth J. Clinical features of women with chronic lower abdominal pain and pelvic congestion. Br J Obstet Gynaecol. 1988;95(2):153-161.

13. Giacchetto C, Catizone F, Cotroneo GB, Cavallaro V, Cammisuli F, Minutolo V, Rodolico G. Radiologic anatomy of the genital venous system in female patients with varicocele. Surg Gynecol Obstet. 1989;169(5):403-407.

14. Park SJ, Lim JW, Ko YT, Lee DH, Yoon Y, Oh JH, Lee $\mathrm{HK}$, et al. Diagnosis of pelvic congestion syndrome using transabdominal and transvaginal sonography. AJR Am J Roentgenol. 2004;182(3):683-688.

15. Soysal ME, Soysal S, Vicdan K, Ozer S. A randomized controlled trial of goserelin and medroxyprogesterone acetate in the treatment of pelvic congestion. Hum Reprod. 2001;16(5):931-939.

16. Farquhar CM, Rogers V, Franks S, Pearce S, Wadsworth J, Beard RW. A randomized controlled trial of medroxyprogesterone acetate and psychotherapy for the treatment of pelvic congestion. Br J Obstet Gynaecol. 1989;96(10):1153-1162.

17. Rundqvist E, Sandholm LE, Larsson G. Treatment of pelvic varicosities causing lower abdominal pain with extraperitoneal resection of the left ovarian vein. Ann Chir Gynaecol. 1984;73(6):339-341.

18. Kim HS, Malhotra AD, Rowe PC, Lee JM, Venbrux AC. Embolotherapy for pelvic congestion syndrome: longterm results. J Vasc Interv Radiol. 2006;17(2 Pt 1):289297. 